\title{
Mouse Model Resources for Vision Research
}

\author{
Jungyeon Won, Lan Ying Shi, Wanda Hicks, Jieping Wang, Ronald Hurd, Jürgen K. Naggert, \\ Bo Chang, and Patsy M. Nishina
}

The Jackson Laboratory, 600 Main Street, Bar Harbor, ME 04609, USA

Correspondence should be addressed to Patsy M. Nishina, patsy.nishina@jax.org

Received 1 July 2010; Accepted 21 September 2010

Academic Editor: Radha Ayyagari

Copyright (๑) 2011 Jungyeon Won et al. This is an open access article distributed under the Creative Commons Attribution License, which permits unrestricted use, distribution, and reproduction in any medium, provided the original work is properly cited.

\begin{abstract}
The need for mouse models, with their well-developed genetics and similarity to human physiology and anatomy, is clear and their central role in furthering our understanding of human disease is readily apparent in the literature. Mice carrying mutations that alter developmental pathways or cellular function provide model systems for analyzing defects in comparable human disorders and for testing therapeutic strategies. Mutant mice also provide reproducible, experimental systems for elucidating pathways of normal development and function. Two programs, the Eye Mutant Resource and the Translational Vision Research Models, focused on providing such models to the vision research community are described herein. Over 100 mutant lines from the Eye Mutant Resource and 60 mutant lines from the Translational Vision Research Models have been developed. The ocular diseases of the mutant lines include a wide range of phenotypes, including cataracts, retinal dysplasia and degeneration, and abnormal blood vessel formation. The mutations in disease genes have been mapped and in some cases identified by direct sequencing. Here, we report 3 novel alleles of $C r x^{t v r m 65}, R p 1^{t v r m 64}$, and $R p e 65^{t v r m 148}$ as successful examples of the TVRM program, that closely resemble previously reported knockout models.
\end{abstract}

\section{Introduction}

The Eye Mutant Resource (EMR) and the Translational Vision Research Models (TVRMs) programs currently housed at The Jackson Laboratory are tailored to provide genetically defined models of vision-associated diseases to the Research Community. The EMR screens for spontaneous mutations in the large production and repository colonies, while the TVRM program screens for chemically induced mutations in third-generation (G3) offspring of mutagenized mice. Both programs are motivated by the need for wellcharacterized models for studying the function of particular molecules in the eye, for examining disease pathology, and for providing a resource to test therapeutic regimens.

In the early phases of the EMR program, the tools for examining mice for ocular abnormalities were adapted for the small size of the mouse eye $[1,2]$. These tools included indirect ophthalmoscopy, slit lamp biomicroscopy, fundus photography, and electroretinography (ERG). Initially, mice from various stocks and inbred strains were screened to identify spontaneous ocular mutants using the first two methodologies. Currently, ERG screening is done as well to identify and characterize new retinal mutants. As secondary screens, fluorescein angiography is used to detect vascular changes [2], and noninvasive tonometry [3] is used to assess changes in intraocular pressure. Screening has also been expanded to include genetically engineered strains from the Jackson Laboratory's Genetic Resource Sciences (GRS) repository that are systematically examined as they are removed from the shelf or are retired from breeding. Also, in addition to the initial phenotypic characterization, the EMR strives to identify the mutations underlying the disorders.

Systematic chemical mutagenesis screens have been successfully carried out in several model organisms, including Drosophila [4], C. elegans [5], and zebrafish [6, 7]. The zebrafish screens have provided valuable eye models, especially those pertaining to eye development [8]. In addition to our efforts, other mutagenesis screens for eye phenotypes in mice have been reported in which a number of mutants have been described [9-11]. Although different methods for mutagenizing mice are available, the alkylating agent, $\mathrm{N}$ ethyl-N-nitrosourea (ENU), is the mutagen most commonly 
used [12]. ENU mainly induces point mutations resulting in a range of consequences including total or partial lossof-function, dominant-negative, or gain-of-function alleles [13-16]. Its effectiveness as a mutagen is dependent on dosage, frequency of administration, and mouse strain. Effectiveness, in terms of identifying mutants, depends upon the type of screen (e.g., dominant versus recessive) and the reproducibility of the phenotypic assay utilized. Mutant recovery has ranged from a rate of $1 / 175$ [17], to $\sim 1 / 666$ in Specific Locus Tests (SLTs) [12], and to an average of 1/1470 based on recessive screening in a defined chromosomal region [18]. The mutation rates for individual loci can vary by almost tenfold $[12,17,18]$.

The majority of large-scale mutagenesis screens have been dominant screens. This is probably due to the relative ease of creating mutagenized mice for dominant screens compared to recessive ones. Screening for dominants on a genome-wide basis can be done in one generation $\left(G_{1}\right)$, while recessives generally require three. The Neuherburg Cataract Mutant Collection of $\sim 170$ dominant mutants was assembled through screening over 500,000 first-generation mice exposed to various mutagens [19]. The GSF-Munich [14] and MRC-Harwell [13, 20] programs were established using a phenotype-based approach to screen thousands of mice for dominant mutations affecting a variety of biological processes. A major drawback to dominant screens, however, is that not all mutations have dominant effects. A dominant screen will, therefore, miss many of the induced mutations. Estimates suggest that the frequency of diseases caused by recessive mutations is $4-10$-fold higher than for dominant ones. In fact, of 218 eye mutants surveyed in the Mouse Genome Informatics Database, 80\% were recessive mutations and only $20 \%$ were dominant or semidominant. Therefore, the TVRM program screened a G3 population of mutagenized mice for recessive mutations.

Screening for spontaneous and chemically induced mutants provides an important source of models to study the effects of single-gene mutations found in human patients. Additionally, new mutations within the same gene provide allelic series in which splice variants or domain-specific effects can be queried. Finally, mutations in novel genes that lead to retinal disorders can be discovered using a forward genetic approach.

\section{Materials and Methods}

2.1. Origins of Mice and Husbandry. The ages at which the visual system is affected by disease can vary considerably. For the EMR program, an initial screen of JAX Mice \& Services (JMSs) production colonies and mice removed from the GRS Repository is routinely performed at $\sim 2$ months of age and if necessary, additional screening is done at an older age, usually at 6 months of age. Also, as with other neuronal diseases, diseases of the visual system are not reversible, so ocular diseases can be captured in retired breeders. Therefore, when available, retired breeders that are older than 1 year of age are screened. C57BL/6J (B6) G3 ENU mutagenized mice were screened by the TVRM program. For

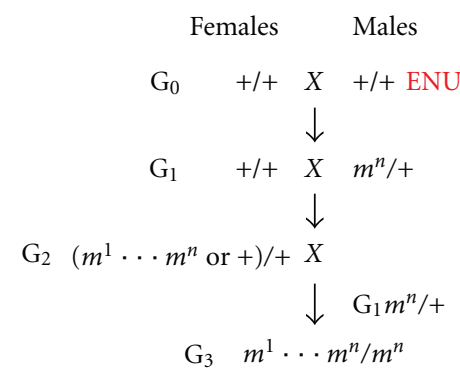

FIGURE 1: Schematic representation of the mating scheme of dominant $\left(G_{1}\right)$ or recessive $\left(G_{3}\right)$ screens. Male mice were mutagenized (3 weekly doses, $80 \mathrm{mg} / \mathrm{kg}$ ) and mated to WT females after 4 weeks. If any female was pregnant within 5 weeks, the mating was discarded. If, however, male mice impregnated a female after that, the resulting $\mathrm{G}_{1}$ males were crossed to their respective female counterparts, and the $G_{2}$ progeny were backcrossed to the $G_{1}$ fathers to generate $G_{3}$ offspring.

the chemically induced mutations, ENU was administered to male B6 mice in three weekly injections of $80 \mathrm{mg} / \mathrm{kg}$. G3 offspring were generated using a three-generation backcross mating scheme (Figure 1). G3 mice were screened at 24 weeks of age in order to enhance our ability to identify late onset diseases.

To determine if the disease phenotype was inheritable, mutant mice were outcrossed to wild-type (WT) mice to generate $\mathrm{F} 1$ progeny with subsequent intercrossing of the resultant F1 mice to generate F2 progeny. Both F1 and F2 mice were examined by indirect ophthalmoscopy or ERG. If $\mathrm{F} 1$ mice were affected, the pedigree was designated as segregating a dominant mutation. If $\mathrm{F} 1$ mice were not affected but $\sim 25 \%$ of F2 mice were affected, the pedigree was designated as segregating a recessive mutation. Once the observed ocular phenotype was determined to be genetically heritable, mutants were bred and maintained in the Research Animal Facility at JAX. Mice were provided with NIH $6 \%$ fat chow diet and acidified water, with 12:12 hour dark:light cycle in pressurized individual ventilation caging which are monitored regularly to maintain a pathogen-free environment. Procedures utilizing mice were approved by the Institutional Animal Care and Use Committee.

2.2. Clinical Evaluation and Electroretinography. Mice, dark adapted for a minimum of 1 hour, were treated with atropine prior to examination by indirect ophthalmoscopy with a 60 or 78 diopter aspheric lens. Fundus photographs were taken with a Kowa small animal fundus camera using a Volk superfield lens held 2 inches from the eye as previously described [2].

For electroretinographic evaluation of mutants, following a 2-hour dark adaptation, mice were anesthetized with an intraperitoneal injection of xylazine $(80 \mathrm{mg} / \mathrm{kg})$ and ketamine $(16 \mathrm{mg} / \mathrm{kg})$ in normal saline. Additional anesthetic was given if akinesia was inadequate. The equipment and protocol used here were those previously described [21]. Briefly, dark-adapted, rod-mediated ERGs were recorded 
with the responses to short-wavelength flashes over 4.0-log unit to the maximum intensity by the photopic stimulator. Cone-mediated ERGs were recorded with white flashes after $10 \mathrm{~min}$ of complete light adaptation. The signals were sampled at $0.8 \mathrm{msec}$ intervals and averaged.

2.3. Genetic Mapping. Genomic DNA was isolated from tail tips using a PBND (PCR buffer with nonionic detergents) preparation, which was adapted from a protocol from Perkin Elmer Cetus [22]. Tail tips were digested in PBND buffer + Proteinase K overnight at $55^{\circ} \mathrm{C}$. Samples were heated to $95^{\circ} \mathrm{C}$ for 10 minutes, and $1 \mu \mathrm{L}$ of the DNA preparation was used in a $12 \mu \mathrm{L}$ PCR reaction. Amplicons were visualized with ethidium bromide after electrophoretic separation on a $4 \%$ agarose gel.

For mapping purposes, phenotypically affected mice, presumed to be homozygous for the mutations, were mated with DBA/2J mice. The resulting F1 offspring were intercrossed to generate F2 offspring if recessive and backcrossed (BC) to WT parental if dominant. Resulting progeny were phenotyped by indirect ophthalmoscopy. DNA isolated from tail tips from a minimum of 10 affected and 10 unaffected mice was pooled and subjected to a genome-wide scan using 48-80 simple sequence length polymorphic markers distributed throughout the genome. Samples used in the DNA pools were tested individually to confirm the map location [23].

2.4. Preparation of RNA Samples and Subsequent Analysis. Total RNA was isolated from whole eyes and brains of affected mutants and B6 mice using TRIzol Reagent (Life Technologies) per manufacturer's protocol. Total RNA was treated with RNase-free DNaseI (Ambion) and quantity was determined using a NanoDrop spectrophotometer (Thermo Scientific). RNA quality was evaluated with an Agilent Technologies 2100 Bioanalyzer. cDNA was generated using the Retroscript kit (Ambion).

Primers to sequence the coding region of the candidate genes were designed from exon sequences obtained from the Ensembl Database. RT-PCR was done using eye cDNA in a $24 \mu \mathrm{L}$ PCR reaction containing $1 \times$ PCR buffer $(10 \mathrm{mM}$ Tris-HCl pH 8.3, $50 \mathrm{mM} \mathrm{KCl}$ ), $250 \mu \mathrm{M}$ of each dATP, dCTP, dGTP, dTTP, $0.2 \mu \mathrm{M}$ of each forward and reverse primer, $1.5 \mathrm{mM} \mathrm{MgCl} 2$, and $0.6 \mathrm{U}$ Taq polymerase. The following PCR program was used: $94^{\circ} \mathrm{C}$ for 1 minute $30 \mathrm{sec}$ followed by 35 cycles of $94^{\circ} \mathrm{C}$ for $30 \mathrm{sec}, 55^{\circ} \mathrm{C}$ for $45 \mathrm{sec}$, and $72^{\circ} \mathrm{C}$ for $45 \mathrm{sec}$, and a final extension of $72^{\circ} \mathrm{C}$ for 2 minutes. PCR products were electrophoresed on a $1 \%$ agarose gel and visualized by ethidium bromide staining. DNA fragments were sequenced on an Applied Biosystems 3730XL (using a $50 \mathrm{~cm}$ array and POP7 polymer).

2.5. Histological Analysis. Mice were asphyxiated by carbon dioxide inhalation, and enucleated eyes were fixed overnight in cold methanol/acetic acid solution $(3: 1, \mathrm{v} / \mathrm{v})$. The paraffin-embedded eyes were cut into $6 \mu \mathrm{m}$ sections, stained by hematoxylin and eosin ( $\mathrm{H}$ and $\mathrm{E})$, and examined by light microscopy.

\section{Results and Discussion}

3.1. Status of the EMR Program. Since its inception in the 1980s, the EMR program has identified and/or imported more than 100 mouse models with ocular abnormalities for research. Table 1 lists some of the retinal degeneration mouse models of human disease developed and/or currently maintained in the EMR that are available to the Research Community. Other models are described on the EMR web page (http://eyemutant.jax.org/).

3.2. Status of the TVRM Program. The TVRM program was built upon the success of the Neuromutagenesis Facility (NMF) at The Jackson Laboratory, and 15 of the 60 mutant lines (Tables 2 and 3) in which a disease phenotype has been subsequently fixed as a coisogenic inbred strain by the TVRM program were first identified in screens conducted by the NMF. The remaining 45 TVRM lines were established by screening $\sim 14,000 \mathrm{G} 3$ mice for anterior and posterior segment abnormalities by indirect ophthalmoscopy and/or slit lamp biomicroscopy. Six of the 60 mutations (10\%) are inherited in a dominant or codominant manner, and the remaining are recessive mutations. Forty six of the mutants have retinal phenotypes ranging between pan-retinal spots or patches, pigmentation defects, and/or attenuation of blood vessels with or without morphological changes that were detectable by light microscopy. Six of the mutant lines have reduced or absent ERG responses for either rod and/or cone cells without photoreceptor loss. Five mutant lines presented with vitreal fibroplasia and three with cataracts. Forty six of the mutations (23 reported in Table 3 ) have been localized to a chromosome, and the molecular basis has been identified for 23 of them (Table 2). Fourteen lines are still in the process of being mapped (data not shown). Nineteen of the 23 mutations in Table 2 were novel alleles in genes in which mutations had previously been reported. Some of these mutants are described below. It should be noted that the current bias for reoccurrences of mutations, herein referred to as remutations, versus identification of novel genes in Table 2 is probably due to the fact that once a mutation is mapped, candidate genes previously associated with an eye disease can be quickly sequenced. Regions containing no obvious candidate genes need to be narrowed further and/or all genes within the region may need to be sequenced to identify the disease-causing mutation.

Interestingly, new phenotypes were observed in 8 of the remutations that have been examined (see; [51-55], personal communication PMN). For example, outer segments (OSs) were either formed abnormally or did not initiate in retinas from homozygous Rpgrip $1^{n m f 247}$ mice [51]. This was in contrast to the Rpgrip $1^{\text {tmlTili }}$ targeted null mutant, hereafter, Rpgrip $1^{-1-}$ in which OS discs were formed and stacked vertically rather than horizontally [56]. Targeted alleles of Lamal were reported to be embryonic lethal [57, 58]. The ENU-induced allele, Lama ${ }^{\text {nmf } 223}$, provides a viable, hypomorphic allele in which abnormalities in the adult animal could be examined. Clinically, vitreal fibroplasia and abnormal retinal vasculature were observed. Histologically, 
TABLe 1: Mouse retinal mutants maintained in the Eye Mutant Resource (EMR) at The Jackson Laboratory.

\begin{tabular}{|c|c|c|c|c|}
\hline Model & Mode & Gene & Chr. & Clinical phenotype \\
\hline$r d 1$ & AR & $P d e 6 b$ & 5 & Early onset, severe retinal degeneration [24] \\
\hline pcd & AR & Agtpbp1 & 13 & Slower retinal degeneration associated with Purkinje cell degeneration [25] \\
\hline$n r$ & $\mathrm{AR}$ & UN & 8 & Progressive retinal degeneration with hyperactive ataxic behavior (nervous) [25] \\
\hline$R d 2$ & $\mathrm{AD}$ & $\operatorname{Prph} 2$ & 17 & Slow progressive retinal degeneration $[26]$ \\
\hline$r d 3$ & $\mathrm{AR}$ & $R d 3$ & 1 & Retinal degeneration, beginning at 3 weeks of age [27] \\
\hline$R d 4$ & $\mathrm{AD}$ & Gnb1 & 4 & Autosomal dominant retinal degeneration $[28]$ \\
\hline Tub & $\mathrm{AR}$ & Tub & 7 & Retinal degeneration, hearing loss, and late-developing obesity, also known as $r d 5$ [29] \\
\hline mnd & $\mathrm{AR}$ & $C \ln 8$ & 8 & Early onset retinal degeneration with a late-onset progressive motor neuron degeneration [30] \\
\hline rd6 & $\mathrm{AR}$ & Mfrp & 9 & Small, white retinal spots and progressive photoreceptor degeneration [31] \\
\hline$r d 7$ & $\mathrm{AR}$ & $N r 2 e 3$ & 9 & Retinal spots and progressive photoreceptor degeneration [32] \\
\hline$r d 8$ & AR & Crb1 & 1 & Focal photoreceptor degeneration [33] \\
\hline$R d 9$ & $\mathrm{XD}$ & $U N$ & $\mathrm{X}$ & Progressive retinal white spotting and degeneration [33] \\
\hline$r d 10$ & $\mathrm{AR}$ & Pde6b & 5 & Early onset, mild retinal degeneration [34] \\
\hline$r d 11$ & $\mathrm{AR}$ & Lpcat1 & 13 & Retinal degeneration with white retinal vessels at 4 weeks of age [35] \\
\hline rd12 & $\mathrm{AR}$ & Rpe65 & 3 & Poor ERG response and late onset retinal degeneration [36] \\
\hline rd14 & $\mathrm{AR}$ & $U N$ & 18 & Slow retinal degeneration with white retinal spots [37] \\
\hline rd15 & $\mathrm{AR}$ & $U N$ & 7 & Retinal degeneration with retinal outer plexiform dystrophy [38] \\
\hline rd16 & $\mathrm{AR}$ & Сер290 & 10 & Early onset retinal degeneration [39] \\
\hline$r d 17$ & $\mathrm{AR}$ & Gnat1 & 9 & Poor rod ERG response and slow retinal degeneration [40] \\
\hline cpfl1 & $\mathrm{AR}$ & Pde6c & 19 & Cone photoreceptor function loss-1 $[41]$ \\
\hline Cpfl2 & $\mathrm{AD}$ & $U N$ & 3 & Cone photoreceptor function loss-2 with white retinal spots [42] \\
\hline cpfl3 & $\mathrm{AR}$ & Gnat2 & 3 & Cone photoreceptor function loss-3 [43] \\
\hline Cpfl4 & $\mathrm{AD}$ & $U N$ & 17 & Cone photoreceptor function loss- 4 [44] \\
\hline cpfl5 & AR & Cnga3 & 1 & Cone photoreceptor function loss-5 [45] \\
\hline cpfl6 & $\mathrm{AR}$ & Hcn1 & 13 & Cone photoreceptor function loss- 6 [46] \\
\hline cpfl7 & $\mathrm{AR}$ & $U N$ & 19 & Cone photoreceptor function loss-7 [47] \\
\hline nob2 & $\mathrm{XR}$ & Cacnalf & $\mathrm{X}$ & Anatomical and functional abnormalities (no b-wave-2) in the outer retina [48] \\
\hline nob3 & $\mathrm{AR}$ & Grm6 & 11 & Retinal functional abnormalities (no b-wave 3) [49] \\
\hline $\operatorname{arrd} 2$ & AR & $M d m 1$ & 10 & Age-related retinal degeneration-2 [50] \\
\hline
\end{tabular}

AR: autosomal recessive, AD: autosomal dominant, XR: X-linked recessive, UN: unknown.

persistent hyaloid vessels and fibrous tissue were found in the vitreal space, and the inner limiting membrane was disrupted [52]. In an allelic series of mutations within the rhodopsin gene, light-induced retinal degeneration was observed. Heterozygous $R h o^{\text {Tvrm } 1}$ and $R h o^{\text {Tvrm } 4}$ mice raised in standard vivarium lighting did not exhibit any morphological changes until exposed to bright light [54]. Previously Rho alleles showed spontaneous and pan-retinal degeneration, even when mice were reared from birth in darkness [59].

\subsection{New Alleles of $C r x^{\text {tvrm65 }}, R p 1^{\text {tvrm64 }}$, and Rpe65 $5^{\text {tvrm } 148}$}

3.3.1. Crx $x^{\text {tvrm65 }}$. tvrm65 segregates as a recessive mutation that is characterized by a pan-retinal, grainy fundus appearance that eventually progresses with age to patches of depigmentation within the central retina (data not shown). The mutation was mapped to chromosome (Chr.) 7 between flanking markers D7Mit75 and D7Mit190. A single nucleotide polymorphic (SNP) marker (SNP ID: RS13479126) served to narrow the interval. Crx , a reasonable biological candidate gene, contained within the minimal interval, was examined for a mutation.

CRX is an evolutionary conserved protein. Mice and humans share a $97 \%$ sequence similarity. To date, two $\mathrm{Cr} x$ transcripts have been reported. The long isoform (Genbank nm_001113330) has 25 additional amino acids (aa) in its $\mathrm{N}$ terminus when compared to the shorter isoform (Genbank nm_007770). A T >A nonsense mutation identified in $\mathrm{Cr} x^{\text {tvrm} 65}$ is located in the last exon and is expected to affect both isoforms. The tvrm65 mutation is predicted to cause an early termination at Leu277 (TTG) of the 323 aa from the longer isoform or at Leu253 of a 299 aa product from the shorter isoform (Figure 2(a)).

Phenotypically, $\mathrm{Cr} x^{\text {tvrm65 }}$ mutants resemble the null mouse model in which the single homeodomain containing region [60] of $\mathrm{Crx}$ was targeted. Homozygous $\mathrm{Cr} x^{t m l C l c}$ mice do not develop OS and photoreceptors degenerate. $\mathrm{Cr} x^{\text {tvrm } 65}$ mutants show a rapid photoreceptor degeneration (Figure 2(b)). At postnatal day (P) 14 and P21, OSs were absent and inner segments (ISs) were rarely observed (Figure 2(b)). By P21, photoreceptor cell bodies were reduced to $\sim 60 \%$ of 
TABle 2: Mouse mutants from the Translational Vision Research Models (TVRMs) program in which the molecular basis for the disease phenotype has been identified.

\begin{tabular}{|c|c|c|c|c|}
\hline Model & Mode & Gene & Chr. & Clinical phenotype \\
\hline tvrm64 & AR & $R p 1$ & 1 & Juvenile onset retinal degeneration \\
\hline$n m f 12$ & AR & Mertk & 2 & Late onset slow degeneration \\
\hline tvrm 148 & $\mathrm{AR}$ & Rpe65 & 3 & Late onset retinal degeneration \\
\hline$n m f 192$ & $\mathrm{AR}$ & Nphp4 & 4 & Early rapid retinal degeneration \\
\hline$n m f 364$ & $\mathrm{AR}$ & Pde6b* & 5 & Early rapid retinal degeneration \\
\hline$n m f 449$ & $\mathrm{AR}$ & Pde6b* & 5 & Early rapid retinal degeneration \\
\hline Tvrm1 & $\mathrm{AD}$ & Rho & 6 & Light inducible retinal degeneration [51] \\
\hline Tvrm4 & $\mathrm{AD}$ & Rho & 6 & Light inducible retinal degeneration [51] \\
\hline Tvrm144 & $\mathrm{AD}$ & Rho & 6 & Light inducible retinal degeneration \\
\hline tvrm65 & AR & Crx & 7 & Early rapid retinal degeneration \\
\hline tvrm27 & $\mathrm{AR}$ & $\operatorname{Trpm} 1$ & 7 & No B-wave \\
\hline tvrm89 & $\mathrm{AR}$ & Myo6 & 9 & Attenuated ERG \\
\hline tvrm84 & $\mathrm{AR}$ & Grm1 & 10 & Attenuated ERG \\
\hline$n m f 246$ & $\mathrm{AR}$ & Uchl3 & 14 & Juvenile onset retinal degeneration \\
\hline$n m f 247$ & $\mathrm{AR}$ & Rpgrip1 & 14 & Early rapid retinal degeneration [52] \\
\hline$n m f 5 a$ & $\mathrm{AR}$ & Pfnd5 & 15 & Early rapid retinal degeneration \\
\hline$n m f 240$ & $\mathrm{AR}$ & Clcn2 & 16 & Early rapid retinal degeneration [53] \\
\hline$n m f 223$ & $\mathrm{AR}$ & Lamal & 17 & Vitreal fibroplasia, vascular abnormalities [54] \\
\hline tvrm124 & $\mathrm{AR}$ & Tulp1* & 17 & Early rapid retinal degeneration \\
\hline$n m f 282$ & $\mathrm{AR}$ & Pde6a & 18 & Early rapid retinal degeneration [55] \\
\hline$n m f 363$ & $\mathrm{AR}$ & Pde6a & 18 & Early rapid retinal degeneration [55] \\
\hline tvrm58 & AR & Pde6a* & 18 & Early rapid retinal degeneration \\
\hline tvrm32 & $\mathrm{AR}$ & $H p s 1^{*}$ & 18 & Pigmentation defect \\
\hline
\end{tabular}

* Established by complementation testing.

TABle 3: Mouse mutants from the Translational Vision Research Models (TVRMs) program in which the molecular basis of the disease phenotype has not yet been identified.

\begin{tabular}{|c|c|c|c|}
\hline Model & Mode & Chr. & Clinical phenotype \\
\hline tvrm9 & $\mathrm{AR}$ & 1 & Retinal spots \\
\hline tvrm113 & AR & 4 & Retinal spots, grainy fundus appearance \\
\hline Tvrm6 & $\mathrm{AD}$ & 7 & Retinal spots \\
\hline tvrm116 & AR & 12 & Retinal spots, late onset \\
\hline tvrm111 & $\mathrm{AR}$ & 14 & Retinal spots \\
\hline$n m f 289$ & AR & 16 & Retinal spots \\
\hline tvrm5 & $\mathrm{AR}$ & 18 & Retinal spots in central retina \\
\hline tvrm10 & $\mathrm{AR}$ & 19 & Retinal spots, coloboma, and vascular defects \\
\hline tvrm77 & $\mathrm{AR}$ & 6 & Central patches \\
\hline tvrm119 & AR & 18 & Retinal patches \\
\hline tvrm127 & AR & 18 & Retinal patches \\
\hline tvrm102 & AR & 6 & Grainy retina \\
\hline tvrm101 & AR & 10 & Grainy retina \\
\hline$n m f 67$ & AR & 7 & Fine web-like fundus appearance \\
\hline Tvrm122 & $\mathrm{AD}$ & 3 & Shiny flecks \\
\hline tvrm64a & $\mathrm{AR}$ & 12 & None, identified through histology, lamination defect \\
\hline tvrm111b & $\mathrm{AR}$ & 8 & Abnormal ERG \\
\hline tvrm87 & AR & 4 & Vitreal fibroplasia \\
\hline tvrm114 & AR & 4 & Vitreal fibroplasia, cataracts \\
\hline tvrm53 & $\mathrm{AR}$ & 7 & Vitreal fibroplasia \\
\hline tvrm85 & $\mathrm{AR}$ & 18 & Vitreal fibroplasia \\
\hline Tvrm49 & $\mathrm{AD}$ & 15 & Cataracts \\
\hline tvrm129 & $\mathrm{AR}$ & 13 & Cataracts \\
\hline
\end{tabular}




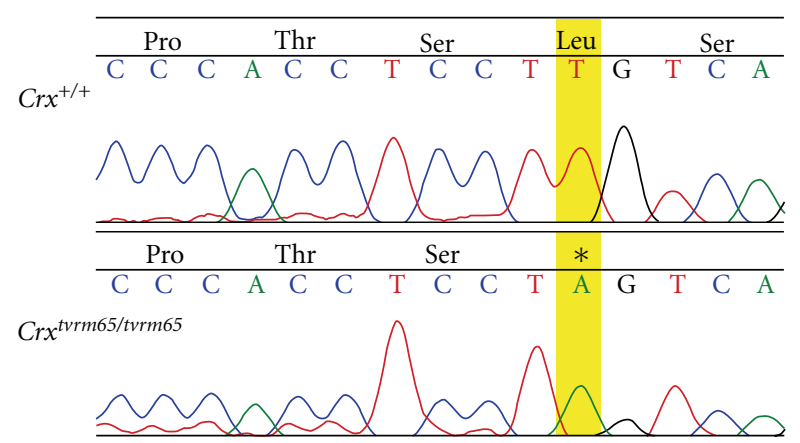

(a)

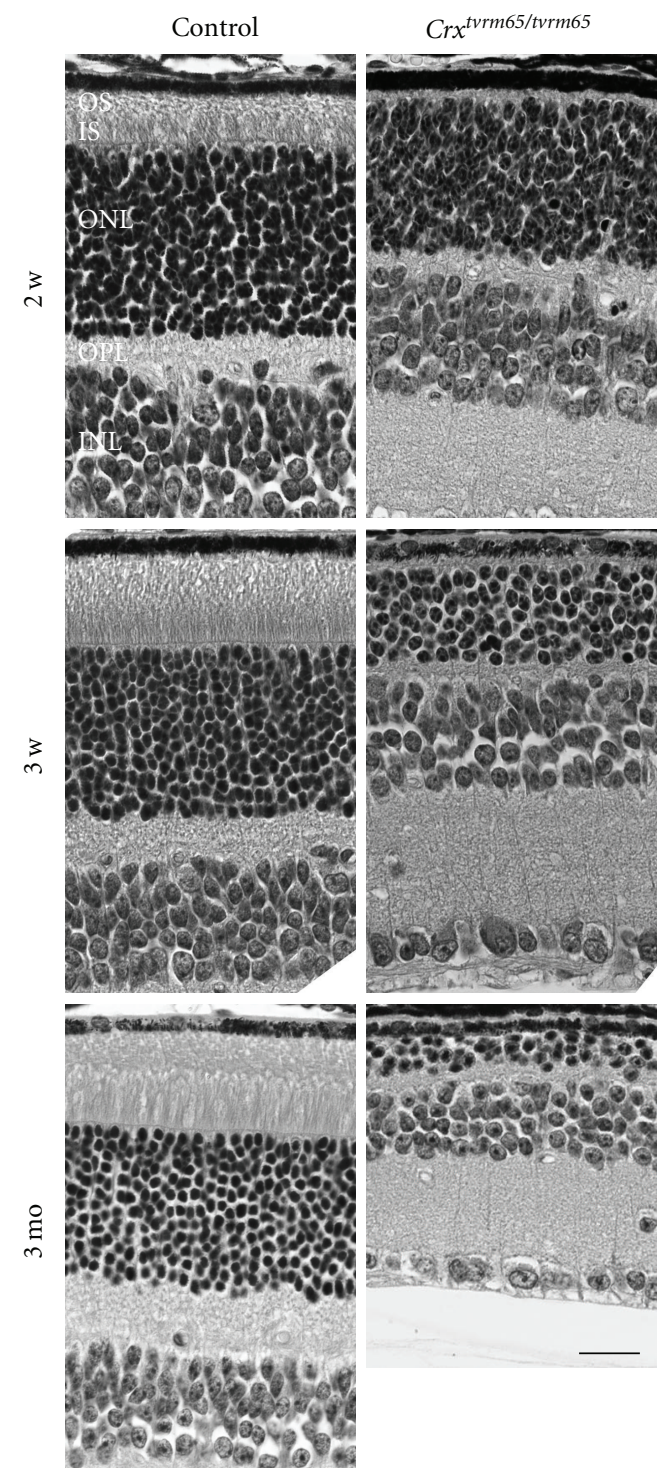

(b)

Figure 2: The mouse model $C r x^{\text {tvrm65 }}$. (a) The mutation in homozygous $\mathrm{Cr} x^{\text {tvrm } 65}$ causes a premature termination at aa residue Leu277. The mutated nucleotide is highlighted (b). Histology of control and $C r x^{\text {tvrm65 }}$ mutant retina at P14, P21, and 3 months of age. OSs were absent at all ages in homozygous $\mathrm{Cr} x^{\text {tvrm65 }}$, and progressive thinning of IS, ONL, and OPL was observed. OSs: outer segments, ISs: inner segments, ONL: outer nuclear layer, OPL: outer plexiform layer, INL: inner nuclear layer. Scale bar $=20 \mu \mathrm{m}$. controls. The outer plexiform layer (OPL) was also thinner, approximately $40 \%$ of controls. By 3 months of age, the OSs and ISs were absent and only 2 3 layers of outer nuclear layer (ONL) were remained. The photoreceptor degeneration observed in the $\mathrm{Cr} x^{\text {tvrm65 }}$ mutants occurs more rapid than reported for the null allele [60]. This may, in part, be due to the difference in genetic background of the two alleles as Cr $x^{\text {tvrm65 }}$ was generated on a B6 background, whereas the previous null allele was described on a segregating B6 and 129 Sb genetic background.

3.3.2. $R p 1^{\text {tvrm64 }}$. tvrm64 segregates as a recessive mutation that is characterized by a grainy fundus appearance and attenuated retinal vessels (data not shown). The mutation mapped to Chr.1 between the centromere and D1Mit427, an interval in which $R p 1$ resides. $R p 1$ encodes a large protein of 2095 aa in mouse and 2156 aa in humans. RP1 localizes in the connecting cilia and appears to play a structural and/or functional role in molecular transport through the connecting cilia $[61,62]$. Mouse RP1 shares $72 \%$ similarity with human RP1. Structurally, it has two ubiquitin homolog (UBQ) domains in its amino terminus. $R p 1$ was tested for a mutation, as the phenotype of homozygous Tvrm64 mutants was similar to that of mice carrying either of two targeted $R p 1$ alleles, involving homologous recombination in which exons 2 and 3 were targeted $\left(R p 1^{t m 1 J n 2}\right)$ [61] or a truncation after codon $662, R p 1^{\text {tm1Eap }}$, analogous to the R667ter mutation in humans [62]. Direct sequencing of homozygous $R p 1^{\text {tvrm64 }}$ retinal cDNA revealed an $\mathrm{A}>\mathrm{T}$ transversion at nucleotide 1769 (Genbank nm_011283), creating a nonsense mutation in which Arg522 (AGA) is changed to a termination codon (TGA; Figure 3(a)). The mutation is localized adjacent to the two UBQ domains in RP1.

The OS length of $R p 1^{\text {tvrm64 }}$ mutant retina was approximately 50\% shorter than WT controls at 1 month of age (Figure 3(b)). The difference in IS length between mutant and controls, however, was barely discernable at 1 month of age but was obviously shorter in $R p 1^{\text {tvrm64 }}$ mutants at 3 months of age. The photoreceptor degeneration was progressive with little difference in cell body number in the ONL at 1 month of age but by 3 months, cell nuclei were reduced to $\sim 50 \%$ in mutants in comparison to controls. In contrast, the photoreceptor morphology of $R p 1^{t m 1 J n 2}$ mice [61] appeared normal by light microscopy at P30 with comparable length of OS in mutant and controls. Also, $R p 1^{t m 1 E a p}$ mice [62] at P30 showed shorter OS lengths and a 1-2-layer reduction in ONL. Therefore, the disease progression in $R p 1^{\text {tvrm64 }}$ at similar age appears to be more severe than observed in $R p 1^{t m 1 J n 2}$ mice but less severe than $R p 1^{\text {tm1Eap }}$ mice.

This difference between the models was also discernable functionally. At 1 month of age, dark-adapted ERGs of $R p 1^{\text {tvrm64 }}$ mice were comparable to WT (Figures 3(c) and $3(\mathrm{~d}))$. In $R p 1^{\text {tm1Eap }}$, these responses were significantly reduced at $4 \sim 5$ weeks of age [62].

3.3.3. Rpe $65^{\text {tvrm } 148}$. The recessive $t v r m 148$ mutation is characterized by late onset retinal spotting and by patches 


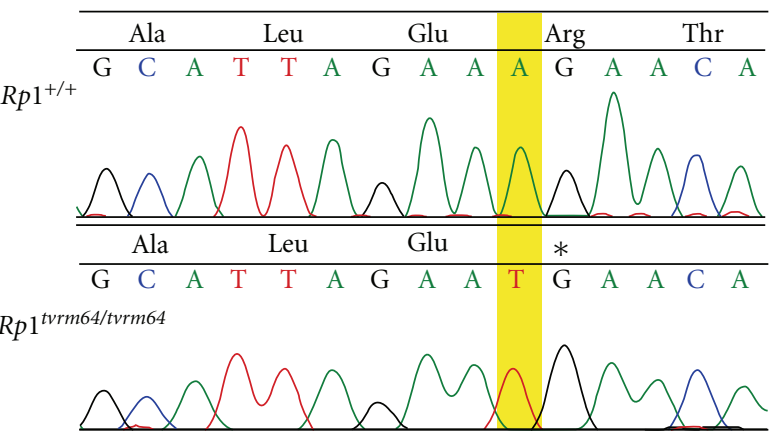

(a)

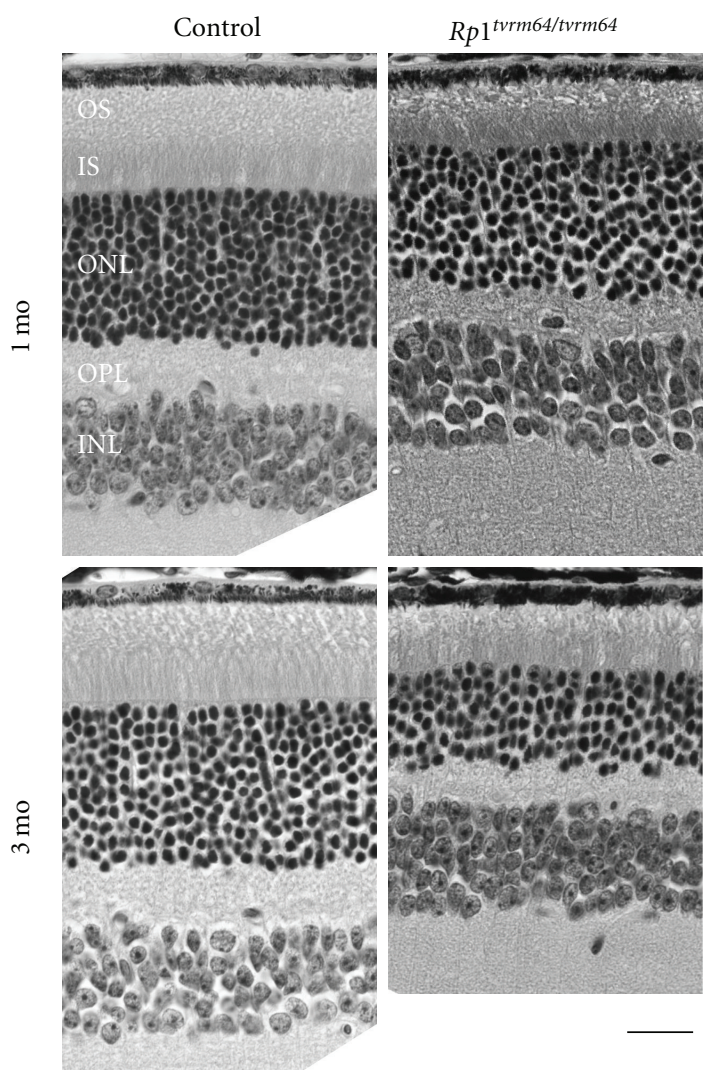

(b)

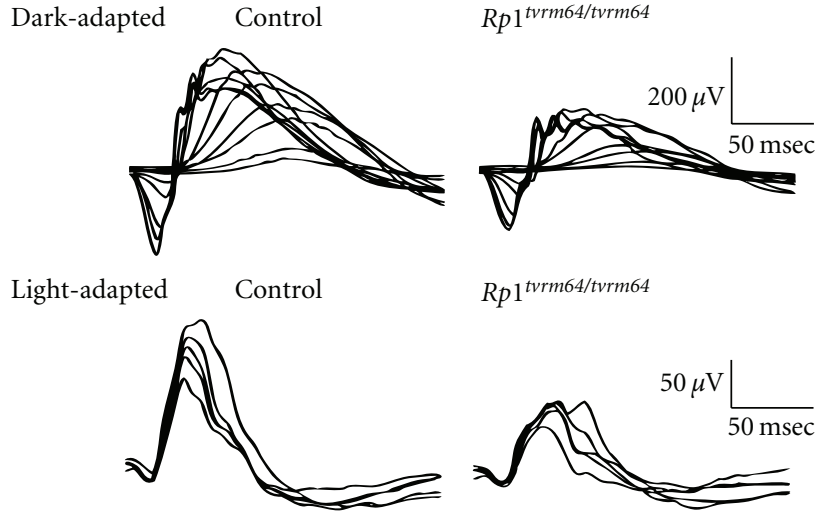

(c)
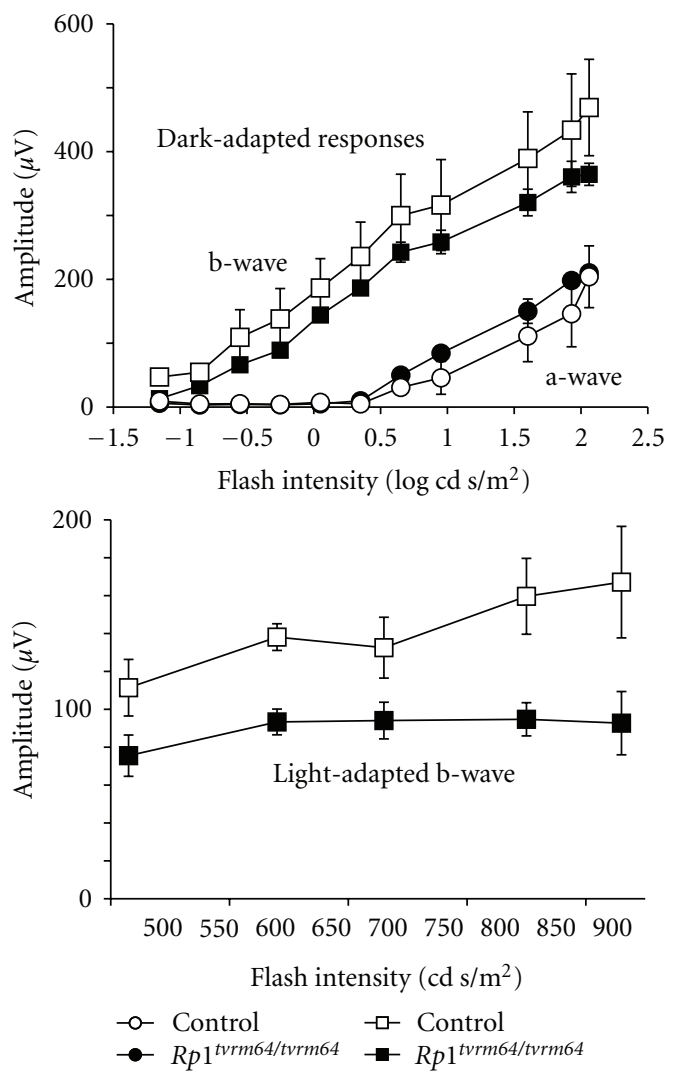

(d)

FIGURE 3: The mouse model $R p 1^{\text {tvrm64 }}$. (a) Direct sequencing of control and $R p 1^{\text {tvrm64 }}$ homozygous mutant identified an A to T mutation, predicting early termination at Arg522. The position of the mutation is highlighted and an asterisk indicates the termination. (b) The retinal morphology of control and $R p 1^{\text {trrm64 }}$ mice was examined at 1 and 3 months of age (mo). OSs: outer segments, ISs: inner segments, ONL: outer nuclear layer, OPL: outer plexiform layer, INL: inner nuclear layer. Scale bar $=20 \mu \mathrm{m}$. (c) Electroretinogram of dark-adapted (scotopic) and light-adapted (photopic) control at 9 weeks of age and $R p 1^{\text {tvrm } 64}$ at 4 weeks of age. (d) The amplitude of dark-adapted a and b-wave and light-adapted b-wave $( \pm$ SEM, $n=3)$ of 4 weeks old $R p 1^{\text {tvrm64 }}$ mice and age matched controls.

of depigmentation that is readily discernable by indirect ophthalmoscopy at 5 months of age (data not shown). The mutation mapped to Chr. 3 between markers, D3Mit147 and D3Mit19. Rpe65 was screened by direct sequencing for a mutation as it fell within the minimal interval identified, and the disease phenotype was similar to that reported for the Rpe65 $5^{\text {tmlTmr }}$ targeted knockout animal (herein referred to as $R p e 65^{-/-}$) [63] and Rpe65 $5^{\text {rd12 }}$ [64] alleles. A $\mathrm{T}>\mathrm{C}$ point mutation was found by direct sequencing of retinal cDNA from Rpe65 $5^{\text {tvrm } 148}$ mice and is expected to generate a mutant protein with an F229S point mutation (Figure 4(a)). F229 is evolutionarily conserved from 


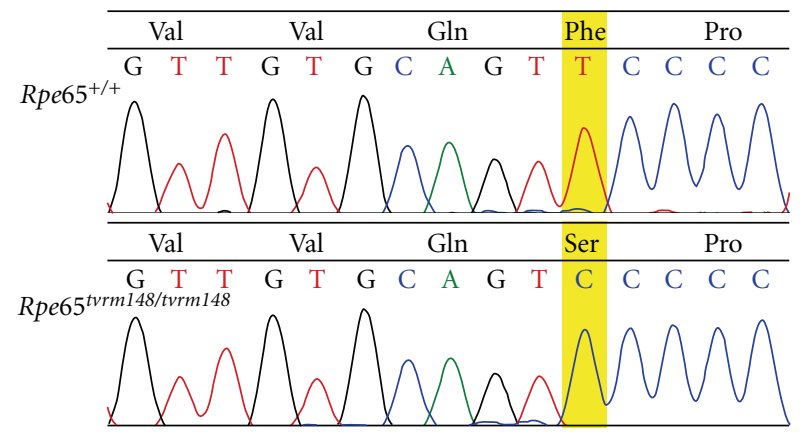

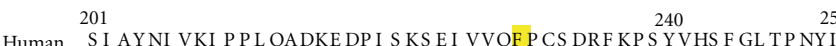

Chimpanzee S I AYNI VKI P P L QA GE F TNL S S S E NKCL Y S L S F TS P F VF L NS F GL T P NY I

Dog S I AYNI VKI P P L QADKE DP I S KS E VVVQF P CS DR F KP S YVHS F GL T P NYI

Cow S I AYNI VKI P PL QADKE DP I S KS E I VVQF P CS DRF KP S Y VHS F GL TP NYI

Mouse TVAYNI I KI P P L KADKE DP I NKS E VVVQF P CS DRF KP S Y VHS F GL T P NYI

Rat TVAYNI I KI P PL KADKE DP I NKS E VVVQF PCS DRF KP S Y VHS F GL T P NY I

Chicken S L AYNI I RI P PL QADKE DP MNKS E VVVQF P CS DRF KP S Y VHS F GL T P NY I

Zebra fish1 S L AYNI VKI P P L QE E KS DP L AMS KVL VQF P S S E RF KP S Y VHS F GMT E NHF

Zebra fish2 S LAYNI VKI P P L QE DKS DQF E KS KI L VQF P S S ERF KP S Y VHS F GI TE NHF

Zebra fish3 SLAYNI VRI P PTQKDKS DP I E KS KVVVQF P S AERF KP S Y VHS F GMT ENYF

(a)

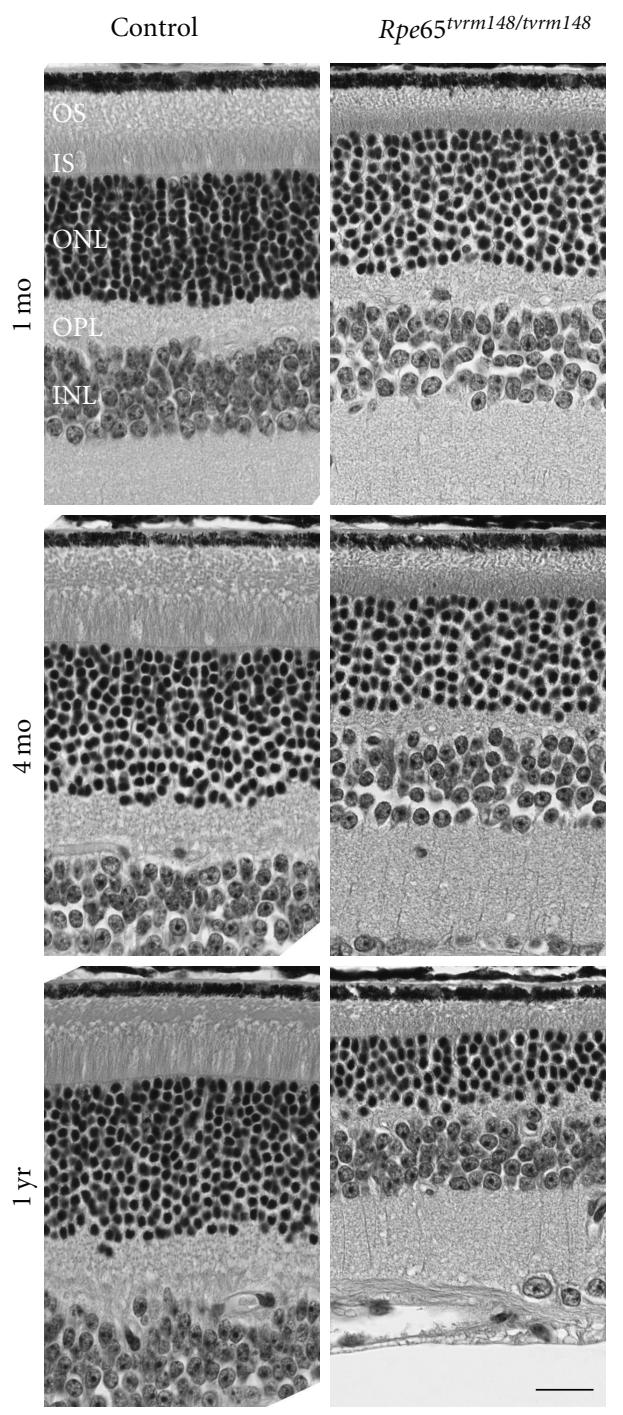

(b)
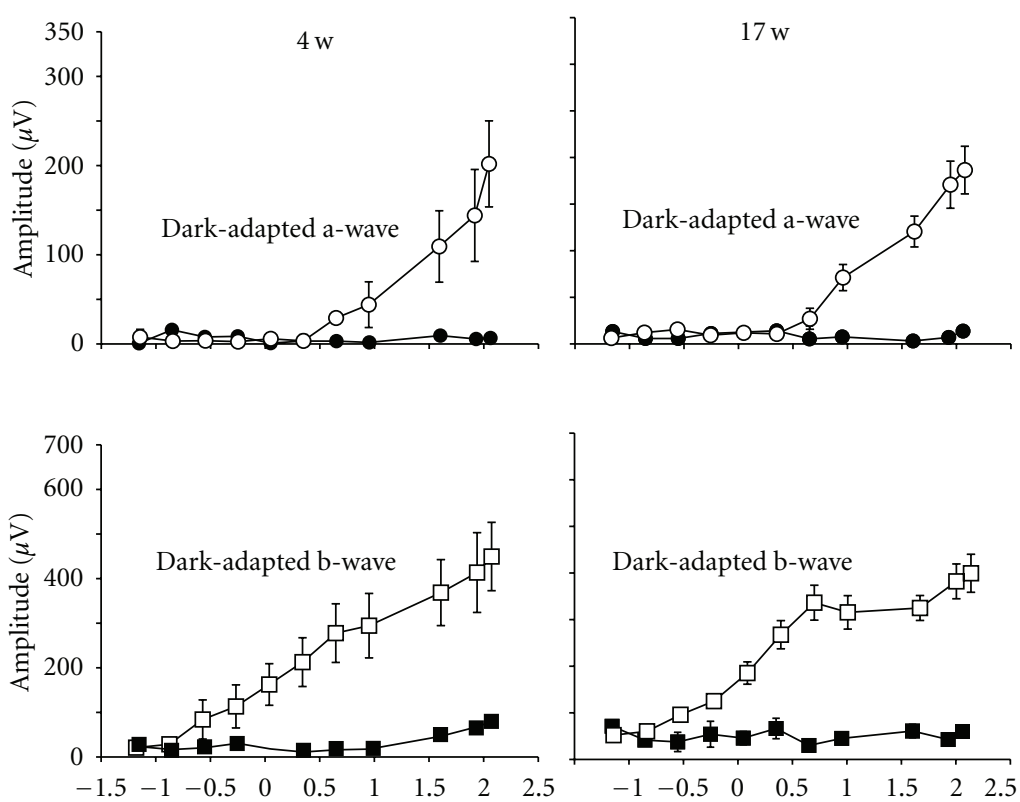

Flash intensity $\left(\log \mathrm{cd} \mathrm{s} / \mathrm{m}^{2}\right)$
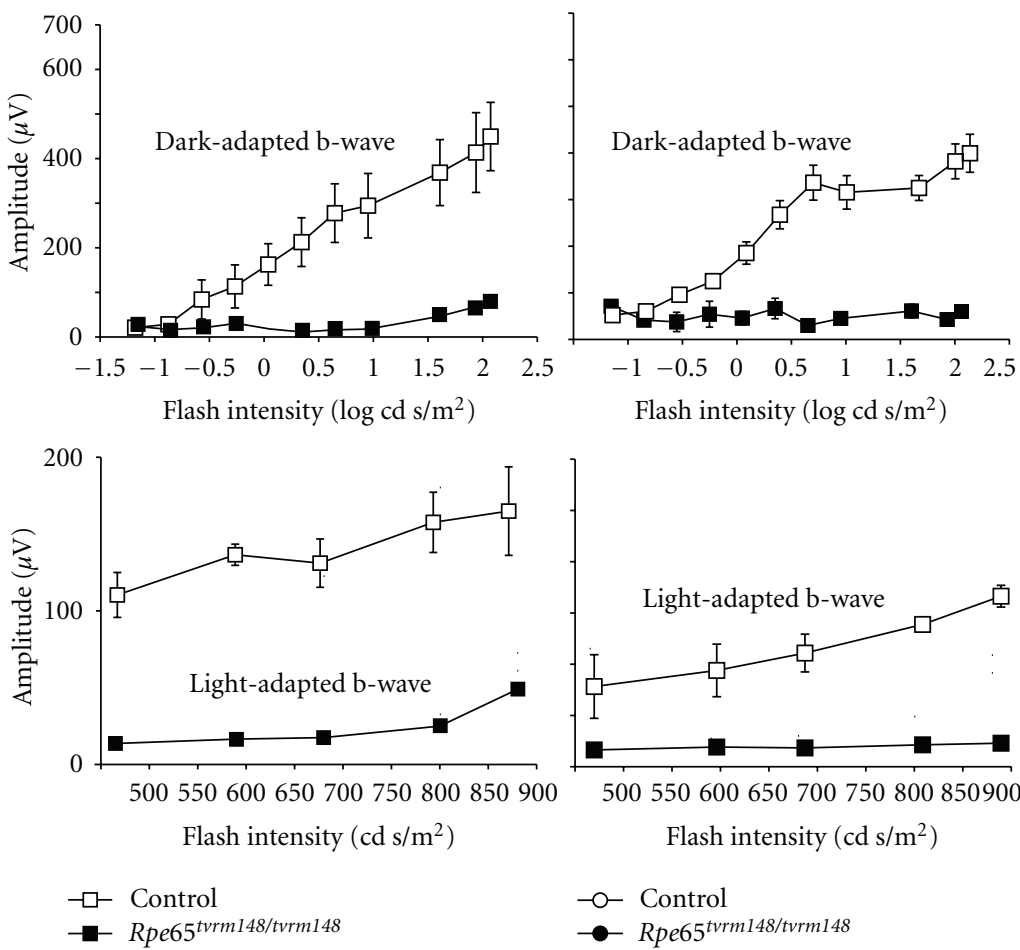

(c)

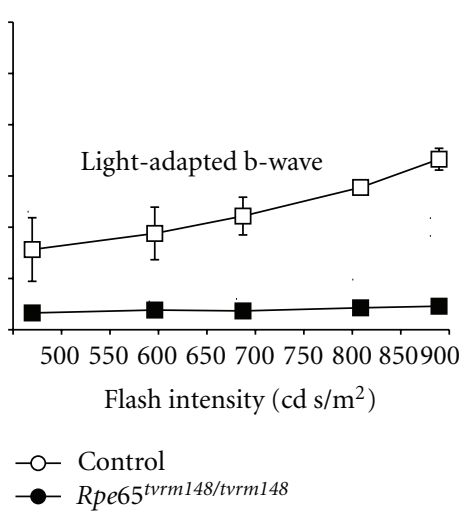

(d)

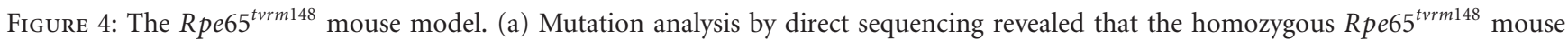
harbored a missense mutation at aa residue 229, causing an amino acid change from Phe to Ser. The highlighted nucleotide indicates the mutation in the Rpe $65^{\text {tvrm148 }}$ mouse (left). RPE65 protein is an evolutionarily conserved protein, and F229 is a nearly invariant residue from human to zebra fish (right). (b) Retinal morphology at 1 and 4 months and 1 year of age was analyzed by light microscopy. ONL thinning was progressive, and IS/OS was shorter than controls at all ages examined. OSs: outer segments, ISs: inner segments, ONL: outer nuclear layer, OPL: outer plexiform layer, INL: inner nuclear layer. Scale bar $=20 \mu \mathrm{m}$. (c, d) Physiological retinal function was analyzed by ERG at 4 weeks (c) and 17 weeks of age (d). The plotted amplitude was obtained at 9 weeks from control and Rpe65 $5^{\text {tvrm } 148}$ mice (c) or at 17 weeks from control and from homozygous Rpe65 $5^{\text {tvrm } 148}$ mice. $N=3$. 
humans to zebra fish but interestingly not in chimpanzee (Figure 4(a)).

The Rpe65 ${ }^{\text {tmlTmr }}$ mutant [63] had a nonfunctional rod ERG response due to the lack of 11-cis-retinal production in the RPE and showed disorganized rod outer segments. Another targeted allele mimicking a human R91W mutation was found in Leber Congenital Amaurosis (LCA2) patients $\left(\right.$ Rpe65 $\left.5^{\text {tmlLreb }}\right)$ [65], and a spontaneous model Rpe65 ${ }^{\text {rd12 }}$ [64] showed a similar disease progression to that observed in Rpe $65^{\text {tvrm } 148}$ mutants. Photoreceptors degenerated progressively in homozygous Rpe $65^{\text {tvrml48 }}$ mouse from 1 month to 1 year of age, the latest time point examined (Figure 4(b)). At 1 month of age, OS and IS lengths were approximately $50 \%$ shorter than controls with no obvious thinning of the ONL. The photoreceptor nuclei were reduced in thickness by $\sim 20 \%$ at 4 months and $\sim 60 \%$ by 1 year of age.

Like the three previously reported mouse models, Rpe65 $5^{\text {tvrm148 }}$ exhibited severely impaired rod ERGs and relatively spared cone ERGs. Rod responses were absent by 4 weeks of age. However, cone b-wave ERGs were comparable to controls at 4 weeks of age but by 17 weeks, the amplitudes were reduced compared to controls (Figures $4(\mathrm{c})-4(\mathrm{~d})$ ).

\section{Conclusions}

4.1. The Utility of Spontaneous and Chemically Induced Mutations. Spontaneous or chemically induced mutations in mice provide a rich source of animal models. These mutations offer some advantages for the study of human genetic diseases and basic gene function over mutations obtained by homologous recombination. First, these mutations are generally identified because they cause a clinically relevant phenotype. By starting with a known phenotype, information about the physiological function of the mutant gene and its biomedical relevance is immediate. Second, the forward genetic approach has the potential for discovery of new genes involved in ocular development and function that were previously unappreciated. Further, spontaneous and chemically induced mutations may better model naturally occurring human genetic conditions. They produce a full and unbiased array of mutation types-single base pair changes or deletions, and in the case of spontaneous mutations, retroviral insertions, repeat sequence expansions, and chromosomal rearrangements. These mutations can create alternatively spliced transcripts or nonsense or missense reading frames. They can abolish all protein function (null), partially diminish function (hypomorphic), or change function (dominant negative or gain-of-function). Moreover, allelic series-collections of mutant alleles of the same gene-can provide domain specific information about protein function and information on alternatively spliced variants. Biomedically relevant phenotypes associated with some human genetic disorders may be revealed by the different alleles that are not replicated by knockout alleles. For example, whereas the null alleles of Lama1 [57, 58] were embryonic lethal, the hypomorphic ENU nmf223 allele allowed for the examination of ocular phenotypes in adult mice [52]. In another example, the $r d 10$ allele of Pde6b [66] identified by the EMR program has a later onset and slower rate of degeneration than the original $r d 1$ allele, thus allowing for the opportunity to test therapeutic strategies [67]. Finally, two phosphodiesterase 6a mutations first described by the TVRM program cause missense mutations that lead to different biochemical outcomes and rates of photoreceptor degeneration, suggesting a difference in the importance of the particular mutant residues to the function of the protein [55].

It should also be noted that spontaneous mutations occur on a wide variety of strain backgrounds, and chemical mutagenesis can be carried out in different genetic backgrounds. The observation of altered mutant phenotypes in different genetic backgrounds can provide a means for identifying interacting genes and molecular pathways of pathophysiology. For example, $N r 2 e 3^{r d 7}$ was observable clinically only in the B6 genetic background [68], and a number of genetic backgrounds act to ameliorate the disease [69]. $\mathrm{Crb1}^{r d 8}$ is observable clinically in the C3H/HeJ background but not in the B6 background [70], and the null mutation is phenotypically different on a segregating 129X1/SvJ and B6 background [71]. Finally, a wide variety of disease phenotypes are observed in $r d 3$ [27] and $G n b 1^{r d 4}$ [28] in different strain backgrounds, indicating interactions with genetic background modifiers. The variation in genetic background enables discovery of modifiers and gene interactions and could be essential to the discovery of important mutant phenotypes and potential targets for therapeutic intervention.

4.2. The Future of the EMR and TVRM Programs. In the future, the EMR will continue to screen for spontaneous mutations in the large production colonies at The Jackson Laboratory. The mutants identified in the TVRM program will be incorporated into the EMR distribution colonies as the molecular bases of the mutations are identified. Finally, sensitized chemical mutagenesis screens are planned that will uncover pathways important in retinal development, maintenance, and function.

\section{Acknowledgments}

The authors would like to thank G. B. Collin and Drs. N. S. Peachey, L. R. Donahue, and R. Smith for careful review of the paper, The Fine Mapping Service for mapping a number of the mutations described herein, The Biological Imaging Service for histology services, and J. Hansen for excellent assistance with animal husbandry. This study was supported by National Institutes of Health Grants nos. EY019943 (BC), EY016501 (PMN) and a TJL institutional core Grant no. CA34196, and by grants from the Foundation for Fighting Blindness (PMN).

\section{References}

[1] B. Chang, N. Hawes, M. Davisson, and J. Heckenlively, "Mouse models of RP," in Retinal Degenerations: Biology, Diagnostics, and Therapeutics, J. Tombran-Tink and C. Barnstable, Eds., pp. 149-164, The Human Press, 2007. 
[2] N. L. Hawes, R. S. Smith, B. Chang, M. Davisson, J. R. Heckenlively, and S. W. John, "Mouse fundus photography and angiography: a catalogue of normal and mutant phenotypes," Molecular Vision, vol. 5, p. 22, 1999.

[3] W.-H. Wang, J. C. Millar, I.-H. Pang, M. B. Wax, and A. F. Clark, "Noninvasive measurement of rodent intraocular pressure with a rebound tonometer," Investigative Ophthalmology and Visual Science, vol. 46, no. 12, pp. 4617-4621, 2005.

[4] C. Nusslein-Volhard and E. Wieschaus, "Mutations affecting segment number and polarity in Drosophila," Nature, vol. 287, no. 5785 , pp. 795-801, 1980.

[5] P. E. Kuwabara, "Worming your way through the genome," Trends in Genetics, vol. 13, no. 11, pp. 455-460, 1997.

[6] W. Driever, L. Solnica-Krezel, A. F. Schier et al., "A genetic screen for mutations affecting embryogenesis in zebrafish," Development, vol. 123, pp. 37-46, 1996.

[7] P. Haffter, M. Granato, M. Brand et al., "The identification of genes with unique and essential functions in the development of the zebrafish, Danio rerio," Development, vol. 123, pp. 1-36, 1996.

[8] J. J. Malicki, Z. Pujic, C. Thisse, B. Thisse, and X. Wei, "Forward and reverse genetic approaches to the analysis of eye development in zebrafish," Vision Research, vol. 42, no. 4, pp. 527-533, 2002.

[9] P. N. Baird, R. H. Guymer, D. Chiu et al., "Generating mouse models of retinal disease using ENU mutagenesis," Vision Research, vol. 42, no. 4, pp. 479-485, 2002.

[10] C. Thaung, K. Arnold, I. J. Jackson, and P. J. Coffey, "Presence of visual head tracking differentiates normal sighted from retinal degenerate mice," Neuroscience Letters, vol. 325, no. 1, pp. 21-24, 2002.

[11] M. M. Jablonski, X. Wang, L. Lu et al., "The Tennessee Mouse Genome Consortium: identification of ocular mutants," Visual Neuroscience, vol. 22, no. 5, pp. 595-604, 2005.

[12] S. Hitotsumachi, D. A. Carpenter, and W. L. Russel, "Doserepetition increases the mutagenic effectiveness of N-ethyl$\mathrm{N}$-nitrosourea in mouse spermatogonia," Proceedings of the National Academy of Sciences of the United States of America, vol. 82, no. 19, pp. 6619-6621, 1985.

[13] M. J. Justice, B. Zheng, R. P. Woychik, and A. Bradley, "Using targeted large deletions and high-efficiency N-ethyl$\mathrm{N}$-nitrosourea mutagenesis for functional analyses of the mammalian genome," Methods, vol. 13, no. 4, pp. 423-436, 1997.

[14] S. D. M. Brown and P. M. Nolan, "Mouse mutagenesissystematic studies of mammalian gene function," Human Molecular Genetics, vol. 7, no. 10, pp. 1627-1633, 1998.

[15] M. Hrabe de Angelis and R. Balling, "Large scale ENU screens in the mouse: genetics meets genomics," Mutation Research, vol. 400, no. 1-2, pp. 25-32, 1998.

[16] R. P. Woychik, M. L. Klebig, M. J. Justice, T. R. Magnuson, and E. D. Avrer, "Functional genomics in the post-genome era," Mutation Research, vol. 400, no. 1-2, pp. 3-14, 1998.

[17] A. Shedlovsky, J. D. McDonald, D. Symula, and W. F. Dove, "Mouse models of human phenylketonuria," Genetics, vol. 134, no. 4, pp. 1205-1210, 1993.

[18] E. M. Rinchik and D. A. Carpenter, "N-ethyl-N-nitrosourea mutagenesis of a 6- to $11-\mathrm{cM}$ subregion of the Fah- Hbb interval of mouse chromosome 7: completed testing of 4557 gametes and deletion mapping and complementation analysis of 31 mutations," Genetics, vol. 152, no. 1, pp. 373-383, 1999.
[19] J. Favor and A. Neuhäuser-Klaus, "Saturation mutagenesis for dominant eye morphological defects in the mouse Mus musculus," Mammalian Genome, vol. 11, no. 7, pp. 520-525, 2000.

[20] S. D. Brown and J. Peters, "Combining mutagenesis and genomics in the mouse-closing the phenotype gap," Trends in Genetics, vol. 12, no. 11, pp. 433-435, 1996.

[21] N. L. Hawes, B. Chang, G. S. Hageman et al., "Retinal degeneration $6(r d 6)$ : a new mouse model for human retinitis punctata albescens," Investigative Ophthalmology and Visual Science, vol. 41, no. 10, pp. 3149-3157, 2000.

[22] R. Higuchi, "Rapid, efficient DNA extraction for PCR from cells or blood. Perkin Elmer Cetus," Amplifications, vol. 2, pp. $1-3,1989$.

[23] B. A. Taylor, A. Navin, and S. J. Phillips, "PCR-amplification of simple sequence repeat variants from pooled DNA samples for rapidly mapping new mutations of the mouse," Genomics, vol. 21, no. 3, pp. 626-632, 1994.

[24] C. E. Keeler, "The inheritance of a retinal abnormality in white mice," Proceedings of the National Academy of Sciences of the United States of America, vol. 10, pp. 329-333, 1924.

[25] R. J. Mullen and M. M. LaVail, "Two new types of retinal degeneration in cerebellar mutant mice," Nature, vol. 258, no. 5535, pp. 528-530, 1975.

[26] R. van Nie, D. Ivanyi, and P. Demant, "A new H-2-linked mutation, rds, causing retinal degeneration in the mouse," Tissue Antigens, vol. 12, no. 2, pp. 106-108, 1978.

[27] B. Chang, J. R. Heckenlively, N. L. Hawes, and T. H. Roderick, "New mouse primary retinal degeneration $(r d-3)$," Genomics, vol. 16, no. 1, pp. 45-49, 1993.

[28] T. H. Roderick, B. Chang, N. L. Hawes, and J. R. Heckenlively, "A new dominant retinal degeneration $(R d 4)$ associated with a chromosomal inversion in the mouse," Genomics, vol. 42, no. 3, pp. 393-396, 1997.

[29] J. R. Heckenlively, B. Change, L. C. Erway et al., "Mouse model for usher syndrome: linkage mapping suggests homology to usher type I reported at human chromosome 11p15," Proceedings of the National Academy of Sciences of the United States of America, vol. 92, no. 24, pp. 11100-11104, 1995.

[30] B. Chang, R. T. Bronson, N. L. Hawes et al., "Retinal degeneration in motor neuron degeneration: a mouse model of ceroid lipofuscinosis," Investigative Ophthalmology and Visual Science, vol. 35, no. 3, pp. 1071-1076, 1994.

[31] N. L. Hawes, B. Chang, G. S. Hageman et al., "Retinal degeneration 6 (rd6): a new mouse model for human retinitis punctata albescens," Investigative Ophthalmology and Visual Science, vol. 41, no. 10, pp. 3149-3157, 2000.

[32] B. Chang, J. R. Heckenlively, N. L. Hawes, and M. T. Davisson, "A new mouse model of retinal dysplasia and degeneration (rd7)," Investigative Ophthalmology \& Visual Science, vol. 39, p. S880, 1998.

[33] B. Chang, N. L. Hawes, R. E. Hurd, M. T. Davisson, S. Nusinowitz, and J. R. Heckenlively, "Retinal degeneration mutants in the mouse," Vision Research, vol. 42, no. 4, pp. 517$525,2002$.

[34] B. Chang, N. L. Hawes, M. T. Pardue et al., "Two mouse retinal degenerations caused by missense mutations in the $\beta$-subunit of rod cGMP phosphodiesterase gene," Vision Research, vol. 47, no. 5, pp. 624-633, 2007.

[35] N. L. Hawes, B. Chang, R. E. Hurd, S. Nusinowitz, J. R. Heckenlively, and M. T. Davisson, "A new mouse model of retinal degeneration (rd11), Investigative Ophthalmology \& Visual Science, vol. 43, E-Abstract 3669, 2002. 
[36] B. Chang, N. L. Hawes, R. E. Hurd, M. T. Davisson, S. Nusinowitz, and J. R. Heckenlively, "A point mutation in the Rpe65 gene causes retinal degeneration ( $r d 12)$ in mice," Investigative Ophthalmology \& Visual Science, vol. 43, EAbstract 3670, 2002.

[37] J. Zhang, N. L. Hawes, J. Wang et al., "A new mouse model of retinal degeneration (rd14)," Investigative Ophthalmology \& Visual Science, vol. 46, E-Abstract 3170, 2005.

[38] N. L. Hawes, R. E. Hurd, J. Wang et al., "A new mouse model of retinal degeneration ( $r d 15)$ with retinal outer plexiform dystrophy," Investigative Ophthalmology \& Visual Science, vol. 46, E-Abstract 3175, 2005.

[39] B. Chang, H. Khanna, N. Hawes et al., "In-frame deletion in a novel centrosomal/ciliary protein CEP290/NPHP6 perturbs its interaction with RPGR and results in early-onset retinal degeneration in the rd16 mouse," Human Molecular Genetics, vol. 15, no. 11, pp. 1847-1857, 2006.

[40] B. Chang, N. L. Hawes, R. E. Hurd, J. Wang, M. T. Davisson, and S. Nusinowitz, "A new mouse model of retinal degeneration (rd17)," Investigative Ophthalmology \& Visual Science, vol. 48, E-Abstract 4513, 2007.

[41] B. Chang, N. L. Hawes, R. E. Hurd, M. T. Davisson, S. Nusinowitz, and J. R. Heckenlively, "A new mouse model of cone photoreceptor function loss (cpfl1)," Investigative Ophthalmology \& Visual Science, vol. 42, p. S527, 2001.

[42] N. L. Hawes, R. E. Hurd, N. Haider et al., "A new mouse model of cone photoreceptor function loss (Cpfl2)," Investigative Ophthalmology \& Visual Science, vol. 44, E-Abstract 4531, 2003.

[43] B. Chang, M. S. Dacey, N. L. Hawes et al., "Cone photoreceptor function loss-3, a novel mouse model of achromatopsia due to a mutation in Gnat2," Investigative Ophthalmology and Visual Science, vol. 47, no. 11, pp. 5017-5021, 2006.

[44] N. L. Hawes, R. E. Hurd, J. Wang et al., "A new mouse model of cone photoreceptor function loss (Cpfl4)," Investigative Ophthalmology \& Visual Science, vol. 45, E-Abstract 3590, 2004.

[45] N. L. Hawes, X. Wang, R. E. Hurd et al., "A point mutation in the Cnga3 gene causes cone photoreceptor function loss (cpfl5) in mice," Investigative Ophthalmology \& Visual Science, vol. 47, E-Abstract 4579, 2006.

[46] B. Chang, N. L. Hawes, R. E. Hurd et al., "A new mouse model of cone photoreceptor function loss (cpfl6) associated with the targeted Hcnl gene mutation," Investigative Ophthalmology \& Visual Science, vol. 47, E-Abstract 2294, 2006.

[47] N. L. Hawes, B. S. Harris, R. E. Hurd et al., "A new mouse model of cone photoreceptor fuction loss (cpfl7)," Investigative Ophthalmology \& Visual Science, vol. 48, E-Abstract 1350, 2007.

[48] B. Chang, J. R. Heckenlively, P. R. Bayley et al., "The nob2 mouse, a null mutation in Cacnalf: anatomical and functional abnormalities in the outer retina and their consequences on ganglion cell visual responses," Visual Neuroscience, vol. 23, no. 1, pp. 11-24, 2006.

[49] D. M. Maddox, K. A. Vessey, G. L. Yarbrough et al., "Allelic variance between GRM6 mutants, Grm6 $6^{\text {nob3 }}$ and Grm6 nob4 results in differences in retinal ganglion cell visual responses," Journal of Physiology, vol. 586, no. 18, pp. 4409-4424, 2008.

[50] B. Chang, M. N. A. Mandal, V. R. M. Chavali et al., "Agerelated retinal degeneration ( $\operatorname{arrd} 2)$ in a novel mouse model due to a nonsense mutation in the Mdml gene," Human Molecular Genetics, vol. 17, no. 24, pp. 3929-3941, 2008.
[51] J. Won, E. Gifford, R. S. Smith et al., "RPGRIP1 is essential for normal rod photoreceptor outer segment elaboration and morphogenesis," Human Molecular Genetics, vol. 18, no. 22, pp. 4329-4339, 2009.

[52] M. M. Edwards, E. Mammadova-Bach, F. Alpy et al., "Mutations in Lamal disrupt retinal vascular development and inner limiting membrane formation," Journal of Biological Chemistry, vol. 285, no. 10, pp. 7697-7711, 2010.

[53] M. M. Edwards, C. Mar de Evsikova, G. B. Collin et al., "Photoreceptor degeneration, azoospermia, leukoencephalopathy, and abnormal RPE cell function in mice expressing an early stop mutation in CLCN2," Investigative Ophthalmology \& Visual Science, vol. 51, no. 6, pp. 3264-3272, 2010.

[54] E. Budzynski, A. K. Gross, S. D. McAlear et al., "Mutations of the opsin gene (Y102H and I307N) lead to light-induced degeneration of photoreceptors and constitutive activation of phototransduction in mice," Journal of Biological Chemistry, vol. 285, no. 19, pp. 14521-14533, 2010.

[55] K. Sakamoto, M. Mccluskey, T. G. Wensel, J. K. Naggert, and P. M. Nishina, "New mouse models for recessive retinitis pigmentosa caused by mutations in the Pde6a gene," Human Molecular Genetics, vol. 18, no. 1, pp. 178-192, 2009.

[56] Y. Zhao, D.-H. Hong, B. Pawlyk et al., "The retinitis pigmentosa GTPase regulator (RPGR)-interacting protein: subserving RPGR function and participating in disk morphogenesis," Proceedings of the National Academy of Sciences of the United States of America, vol. 100, no. 7, pp. 3965-3970, 2003.

[57] F. Alpy, I. Jivkov, L. Sorokin et al., "Generation of a conditionally null allele of the laminin $\alpha 1$ gene," Genesis, vol. 43, no. 2, pp. 59-70, 2005.

[58] S. Schéele, M. Falk, A. Franzén et al., "Laminin $\alpha 1$ globular domains 4-5 induce fetal development but are not vital for embryonic basement membrane assembly," Proceedings of the National Academy of Sciences of the United States of America, vol. 102, no. 5, pp. 1502-1506, 2005.

[59] M. I. Naash, H. Ripps, S. Li, Y. Goto, and N. S. Peachey, "Polygenic disease and retinitis pigmentosa: albinism exacerbates photoreceptor degeneration induced by the expression of a mutant opsin in transgenic mice," Journal of Neuroscience, vol. 16, no. 24, pp. 7853-7858, 1996.

[60] T. Furukawa, E. M. Morrow, T. Li, F. C. Davis, and C. L. Cepko, "Retinopathy and attenuated circadian entrainment in Crxdeficient mice," Nature Genetics, vol. 23, no. 4, pp. 466-470, 1999.

[61] J. Gao, K. Cheon, S. Nusinowitz et al., "Progressive photoreceptor degeneration, outer segment dysplasia, and rhodopsin mislocalization in mice with targeted disruption of the retinitis pigmentosa-1 (Rp1) gene," Proceedings of the National Academy of Sciences of the United States of America, vol. 99, no. 8, pp. 5698-5703, 2002.

[62] Q. Liu, A. Lyubarsky, J. H. Skalet, E. N. Pugh Jr., and E. A. Pierce, "RP1 is required for the correct stacking of outer segment discs," Investigative Ophthalmology and Visual Science, vol. 44, no. 10, pp. 4171-4183, 2003.

[63] T. M. Redmond, S. Yu, E. Lee et al., "Rpe65 is necessary for production of 11-cis-vitamin A in the retinal visual cycle," Nature Genetics, vol. 20, no. 4, pp. 344-351, 1998.

[64] J.-J. Pang, B. Chang, N. L. Hawes et al., "Retinal degeneration 12 ( $r d 12)$ : a new, spontaneously arising mouse model for human Leber congenital amaurosis (LCA)," Molecular Vision, vol. 11, pp. 152-162, 2005.

[65] M. Samardzija, J. von lintig, N. Tanimoto et al., "R91W mutation in Rpe65 leads to milder early-onset retinal dystrophy 
due to the generation of low levels of 11-cis-retinal," Human Molecular Genetics, vol. 17, no. 2, pp. 281-292, 2008.

[66] B. Chang, N. L. Hawes, M. T. Pardue et al., "Two mouse retinal degenerations caused by missense mutations in the beta-subunit of rod cGMP phosphodiesterase gene," Vision Research, vol. 47, no. 5, pp. 624-633, 2007.

[67] J.-J. Pang, S. L. Boye, A. Kumar et al., "AAV-mediated gene therapy for retinal degeneration in the rd10 mouse containing a recessive $\mathrm{PDE} \beta$ mutation," Investigative Ophthalmology and Visual Science, vol. 49, no. 10, pp. 4278-4283, 2008.

[68] N. B. Akhmedov, N. I. Piriev, B. Chang et al., "A deletion in a photoreceptor-specific nuclear receptor mRNA causes retinal degeneration in the $r d 7$ mouse," Proceedings of the National Academy of Sciences of the United States of America, vol. 97, no. 10, pp. 5551-5556, 2000.

[69] N. B. Haider, W. Zhang, R. Hurd et al., "Mapping of genetic modifiers of $N r 2 e^{3 r d 7 / r d 7}$ that suppress retinal degeneration and restore blue cone cells to normal quantity," Mammalian Genome, vol. 19, no. 3, pp. 145-154, 2008.

[70] A. K. Mehalow, S. Kameya, R. S. Smith et al., "CRB1 is essential for external limiting membrane integrity and photoreceptor morphogenesis in the mammalian retina," Human Molecular Genetics, vol. 12, no. 17, pp. 2179-2189, 2003.

[71] S. A. van de Pavert, A. Kantardzhieva, A. Malysheva et al., "Crumbs homologue 1 is required for maintenance of photoreceptor cell polarization and adhesion during light exposure," Journal of Cell Science, vol. 117, no. 18, pp. 41694177, 2004. 


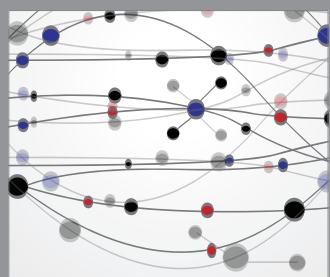

The Scientific World Journal
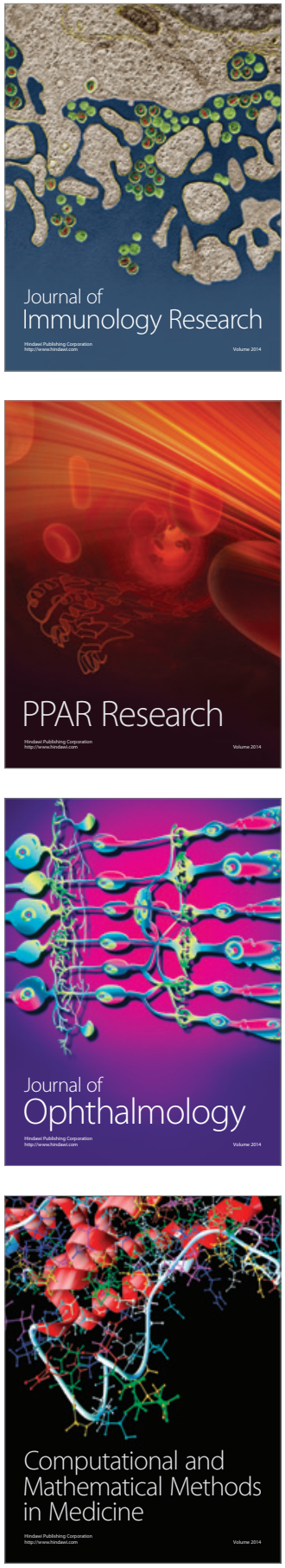

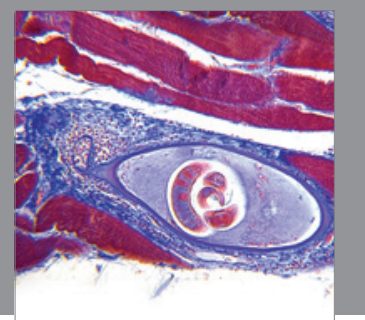

Gastroenterology

Research and Practice
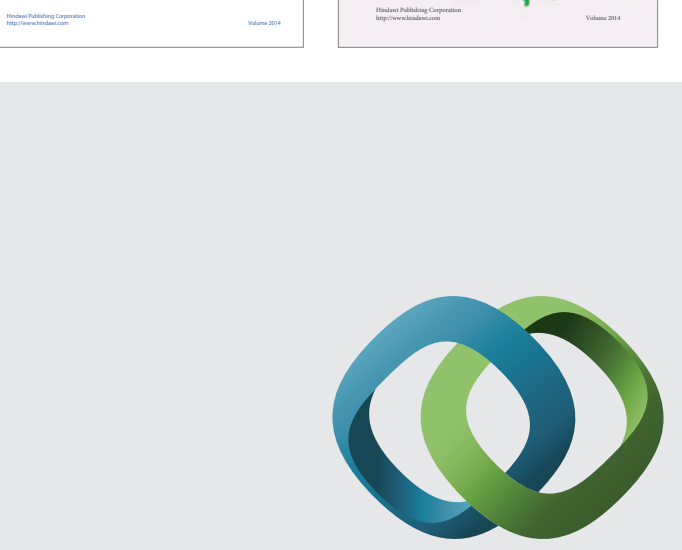

\section{Hindawi}

Submit your manuscripts at

http://www.hindawi.com
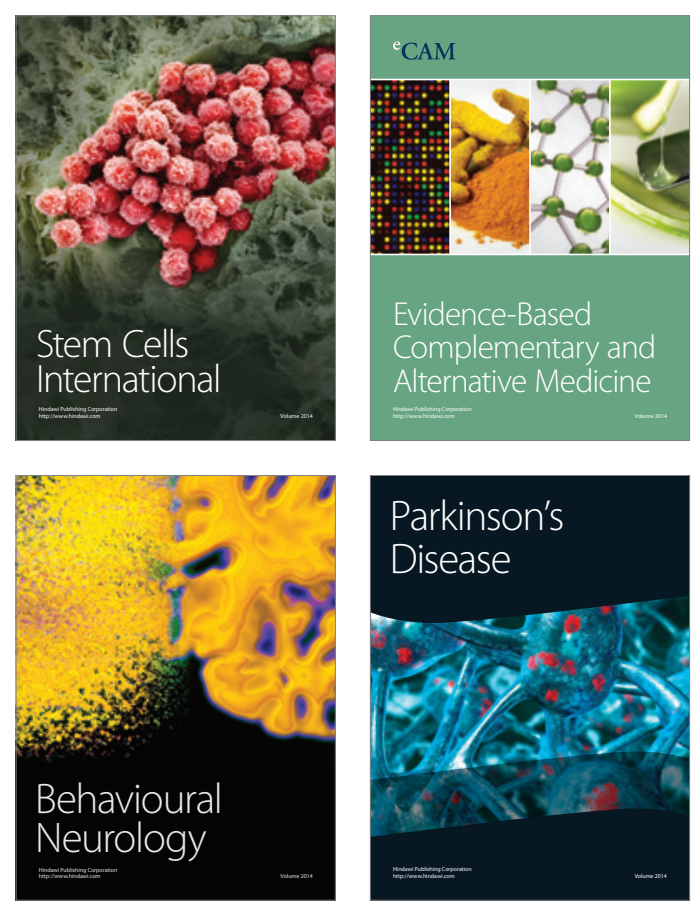

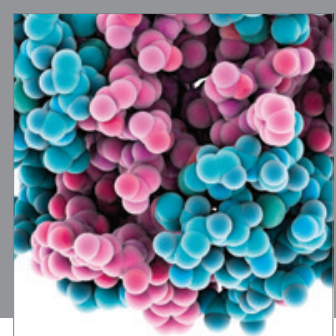

Journal of
Diabetes Research

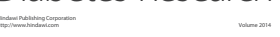

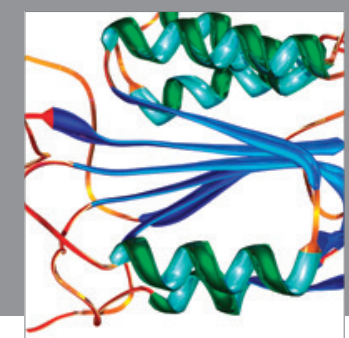

Disease Markers
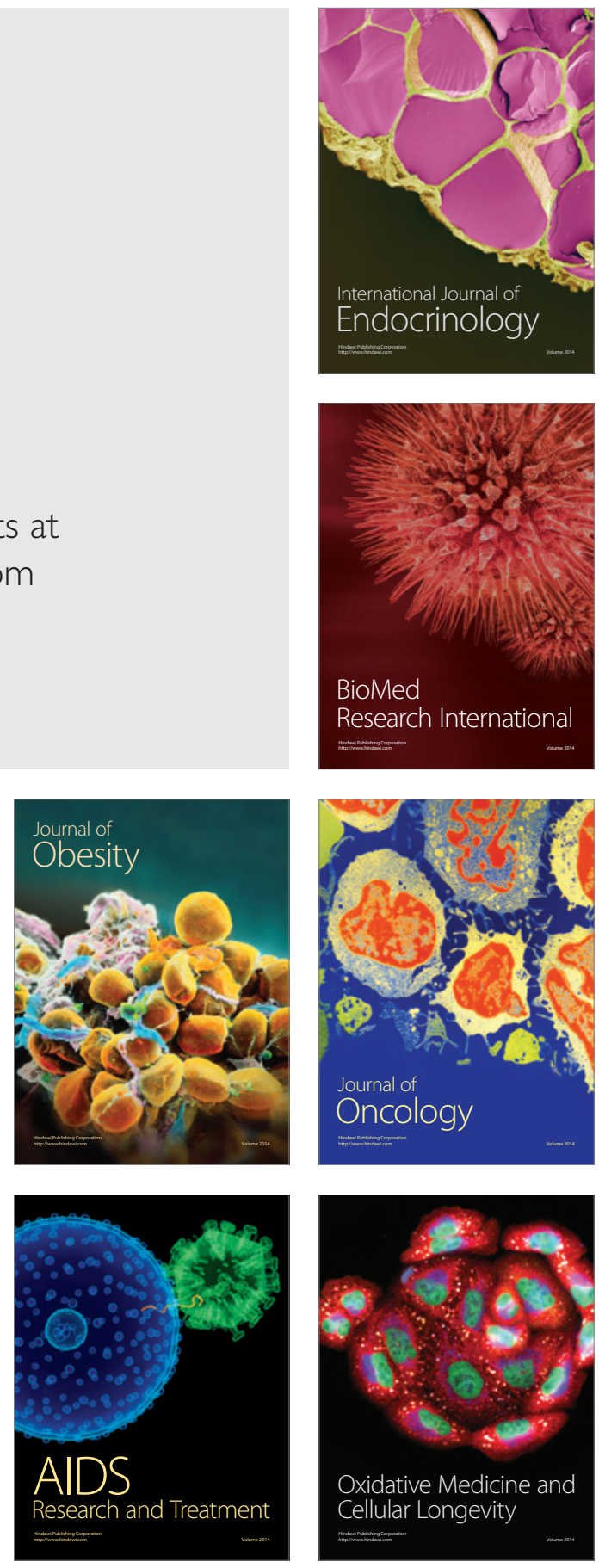